\title{
A Study of Class Size Effects in English School Reception Year Classes
}

\author{
PETER BLATCHFORD, HARVEY GOLDSTEIN, CLARE MARTIN \& \\ WILLIAM BROWNE, Institute of Education, University of London
}

ABSTRACT This article reviews the existing evidence on the relationship between class size and achievement for children in their first years of schooling. It then describes a large-scale longitudinal study of such children within English Local Education Authorities and presents results for achievement progress in literacy and mathematics during the reception year. Using a series of multilevel models, it is shown that there is a relationship with size of class, after various confounding factors have been allowed for, and that there are interactions between class size and initial achievement and between class size and entitlement to free school meals. It is argued that these results, especially the differential effects for different groups of children, could have important implications for educational policy.

\section{Introduction}

There has been a good deal of controversy about the effects of class size differences on pupils' educational attainments. In the UK, debate has been about the negative effects of large classes, while in the USA, debate has centred on the efficacy and cost-effectiveness of class size reductions. There are profound policy implications, not the least because class size reduction initiatives - such as those now introduced into a number of states in the USA (Finn \& Achilles, 1999), as well as the recent UK Government's pledge on maximum class sizes of 30 in all infant classes - are extremely costly. There are also policy implications concerning the exact size of class in relation to academic achievement. There is a common view, based on the US research, that class size reductions below 20 are necessary before effects on achievement become noticeable (Blatchford \& Mortimore, 1994), though this has not been tested in other countries, such as the UK. There is some consensus that class size effects are most marked in the case of the youngest children in school, in the first years after school entry (Blatchford \& 
Mortimore, 1994), and also in the case of minority or poor children (Finn \& Achilles, 1999; Molnar et al., 1999), though once again, information on children in UK schools is not available.

The concept of class size is not straightforward, as we take up in more detail elsewhere (Blatchford et al., 1998). A pupil will experience class sizes varying from day to day as well as within days. The size of class recorded on a register will not be that experienced all the time by all pupils. For the purpose of the present study, however, we have used the registered class size for the three terms of the reception year. Another complication is that in many schools children will be recruited into the reception year at the beginning of each term, depending on their age, so that in general the experienced class size will increase throughout the year. In our analyses, which we report in this article, we use the average class size experienced by each pupil. In addition, we adjust for the term of entry to school.

Much existing research on class size effects has been carried out and has been summarised, for example, by Slavin (1989) and Blatchford \& Mortimore (1994). More recently, a meta-analysis has been carried out (Yang et al., 2000) which identifies nine existing studies of primary school children which satisfy basic quality criteria, such as collecting accurate data on class sizes, having assessment information at the start and end of the period being examined (or having adequate randomisation) and having a large enough sample size. The principal conclusions (see also Goldstein \& Blatchford, 1998) may be summarised as follows:

- a reduction in achievement of about 0.2 standardised units for an increase in class size of 10 pupils above a class size of 15 . Some evidence for a non-linear relationship;

- smaller class size effects with increasing age/grade;

- evidence that class size effect is larger for disadvantaged pupils.

The largest, and arguably most important, study to date is the STAR project carried out in the state of Tennessee in the late 1980s (Word et al., 1990). This was a randomised controlled trial (RCT) whereby 65 schools with at least three entry forms were selected and children randomly assigned to small (about 15), regular (about 25), and regular with teacher-aide classes. The study children were followed for up to 6 years. By contrast, other studies, while satisfying quality design criteria, have involved much smaller numbers of pupils and classes. Nevertheless, Yang et al. (2000) showed that there was good agreement on the magnitude of class size effects among these studies.

A main point to make is that we lack in the UK research on the effects of class size differences. Such research as has been done has not employed research designs strong enough to arrive at unambiguous conclusions. It is commonly assumed that experimental research, such as the STAR project, can provide the best evidence on the causal effect of class size differences. However, a number of authors have noted weaknesses in the STAR study (see Goldstein \& Blatchford [1998] for further details and for a general discussion of the relative merits of RCTs and naturalistic studies in educational research). The principal ones are as follows:

1. 'contamination' of effects among classes of different sizes within same schools. Cluster randomisation would have been better;

2. zero blind because all the participants, including children, knew which treatment they were in;

3. lack of entry assessment to improve precision and inference details and check on randomisation; 
4. applicable strictly only to large schools-uncommon in Britain;

5. the classes tend to be smaller than in the UK and are therefore not very informative about the more common class sizes experienced in British primary schools.

Despite these problems, which limit the usefulness of the STAR study, its general conclusions are in line with others and, as we shall see, also in line with those from the study here reported.

The Institute of Education Class Size Project was set up to answer, for the first time in the UK, questions about the effect of class size differences on pupils' academic progress. The study had a number of features that were designed to be an improvement on previous research. In line with the limitations just cited concerning experimental designs, in the present study, an 'observational' approach was adopted rather than an interventionist one involving random assignment, and a longitudinal design with baseline assessment was used in order to adjust for possible purposive or non-random selection of children into classes on the basis of their pre-existing achievement. The study followed a large sample of children from school entry through the infant stage, i.e. children aged 4-7 years. It used a multimethod approach drawing on a range of sources of data, and used multilevel statistical procedures to model effects of class size differences while controlling for sources of variation that might affect the relationship with academic achievement. Models are fitted that allow for the hierarchical structure of educational data, i.e. that allow for between-pupil, between-classroom and betweenschool variation. In using an 'observational' design, we were able to capture the nature of the relationship between class size and achievement across the full range of observed class sizes (not just a restricted range, as in the case of the STAR project), and this seems important for policy recommendations-for example, in terms of whether certain class sizes or bands of class sizes have stronger effects than others. We also employ a more sophisticated approach to modelling the relationship between class size and achievement than that conducted in previous research, where a simple linear relationship is often assumed, though not tested.

The attribution of causality on the basis of an observational study is clearly important. The key issue is whether the relationships observed between class size and achievement can be due to further 'confounding' factors which have not been accounted for. We have already alluded to the possibility that children are allocated to classes in such a way that the initially low achieving children enter smaller classes. If this were the case, then this could induce a subsequent association between class size and achievement solely due to the initial allocation process. The ways in which this could occur may be subtle, involving judgements by teachers, information from parents, etc. In the present study, we have attempted to adjust for such effects by taking baseline measurements on entry to reception class and fitting linear and non-linear model adjustments for these. It is possible, of course, that such measures are insufficient to account for all 'assignment' factors; we have therefore made further adjustment using free school meal eligibility which acts as a proxy for poverty. Nevertheless, there remains the possibility that some or all of the relationships that we find could be accounted for by further factors and the reader is asked to bear this in mind when interpreting the results. We shall return to this issue in the discussion.

In this article, we report results concerning the first year in English infant schools - the reception year-which allows comparisons with previous research, in which, as we have seen, effects soon after school entry have been most evident. As previous research also suggests that smaller classes are more beneficial for some groups of children, e.g. poor or minority children, we also assess whether class size effects, if they exist, are modified 
in any way by the characteristics of the children entering schools, in particular in terms of gender, family income and attainment on entry to school. We also provide an initial assessment of the extent to which the relationship between class size and achievement is affected by the composition of the class, in terms of the deviation of children's scores from the average.

\section{Method}

\section{Samples}

Starting in 1996, children starting school in the reception year were recruited to the study. The study followed two large cohorts of children over the first three years of school (i.e. the whole of Key Stage 1 (KS1): Reception year, Year 1 and Year 2; 4-7 years). The first cohort started school in 1996, and the second in 1997. Some 220 schools, with 368 classes and 9330 children in eight Local Education Authorities (LEAs) were involved in cohort 1 ; cohort 2 involved a further five LEAs. The present analyses use only cohort 1 . The research design involved a random selection of schools within the participating LEAs. All children entering reception in a selected school during the year were included in the study.

\section{Data Collection}

School entry assessment. Information was collected when pupils entered school by means of a baseline entry assessment conducted by the teacher. The procedure was the Avon Reception Entry Assessment (1996), which covers literacy and mathematics and comprises information from teacher ratings, based on classroom observations, and tasks completed by children. A measure of literacy knowledge was derived by adding for each child scores on 15 items in language, 18 in reading, 17 in writing and a test of letter identification (how many of 26 letters were recognised in terms of either name or sound), and a measure of mathematics was based on total correct out of 19 items. Training was provided for class teachers in its use.

End of reception year assessment. At the end of the reception year, the Literacy Baseline component of the Reading Progress Test (2000) was administered by teachers. It reflects well the literacy curriculum experienced by children in English schools, is consistent with the school entry assessment, and covers phonological awareness, concepts about print, letter knowledge, word reading, spelling/writing and a specially developed teacheradministered test covering understanding of number. In the case of mathematics, a teacher-administered test was devised and piloted. The final version was again designed to cover the curriculum experienced by children and covered counting, repeating patterns, comparison and matching, addition using pictures, subtraction using pictures, addition and subtraction using words, addition and subtraction using symbols, and shape recognition.

Termly questionnaires. A termly questionnaire on class sizes and classroom activities during a half-day period was also completed each term by the class teacher. This collected detailed data on registered and 'experienced' class size (i.e. the class size on the register and the class size as experienced by children at the given survey point), and number of adults present; data on proportions of time devoted to teaching and non-teaching activities; information on within-class grouping practices (size and number 
TABLE I. Variables used in analysis

Variable

Average class size

Entry time

Literacy

Mathematics

Age

Free school meals
Description

Registered class size experienced by pupil averaged over terms in reception class Whether entered school in autumn (78\%), summer or spring

Assessment of reading at baseline and end of reception year

Assessment of mathematics at baseline and end of reception year

Age at 1 September 1996

Whether entitled to free school meals

of groups, group composition in terms of ability, friendship and age mix, the role of adults, and curriculum, task and activity type); time in different curriculum areas; and the frequency and amount of reading activities.

Pupil background information. Pupil background details, including age, sex, free school meal entitlement, English language fluency, previous nursery education, attendance and special educational needs were also collected.

Other information collected included pupil behaviour ratings (completed by teachers on individual pupils), structured observations of classroom interactions and information on teachers, but these are not reported here.

\section{Results}

We present results for mathematics and literacy. The variables used in the present analyses are given in Table I.

A number of preliminary explorations of the data suggested that the modelling of class size effects should be restricted to class sizes from 10 to 35 and for mathematics from 15 to 33 . A few very small and very large classes appeared to be anomalous and have been excluded. Class size itself is measured about an origin of 30, which partly reflects the apparent importance attached to this 'threshold' by educators and policy-makers. Almost all previous studies have limited themselves to linear relationships between achievement and class size, but this may only be true over a restricted range. Fitting simple polynomial relationships may impose too-rigid constraints on the shape of the relationship, especially at the extremes. We have therefore explored various regression spline approaches whereby an underlying polynomial relationship is modified by the addition of smoothly joining local polynomials at selected 'knots'. We have also studied more general fractional polynomials but these appear to add little and have not been used. The cubic regression spline which we have used (see, for example, Hastie \& Tibshirani, 1990) is defined as follows:

$$
\begin{aligned}
& y_{i}=\sum_{h=0}^{3} \beta_{h} x_{i}^{h}+\alpha_{1}\left(x_{i}-k_{1}\right)_{+}^{3}+\alpha_{1}\left(k_{2}-x_{i}\right)_{+}^{3} \\
& k_{1}>k_{2} \\
& \text { where }(z)_{+}=\left\{\begin{array}{l}
0 \text { if } z<0 \\
z \text { if } z \geq 0
\end{array}\right.
\end{aligned}
$$

The knots $k_{1}, k_{2}$, are chosen to provide the best smoothed relationship over the range of class sizes fitted. The function of the upper and lower splines is to avoid the end points having too much influence over the overall shape of the relationship. It is possible to choose more than two knots but we have not pursued this. We require that the 


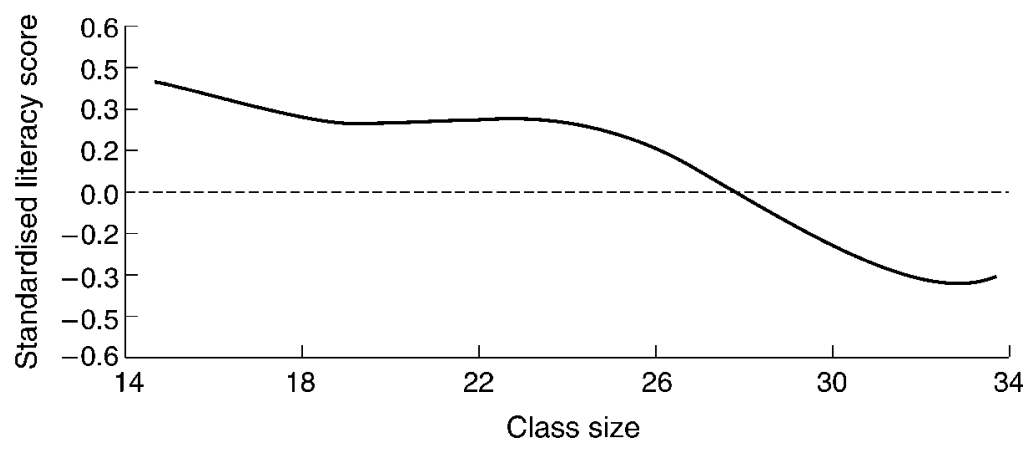

FIG 1. Post-reception literacy by class size (knots at 19, 25).

relationship, as far as possible, be decreasing (or increasing) over the range of class sizes from about 15 to 30. The knots finally chosen are at class sizes of 19 and 25, but the overall results are not markedly sensitive to the precise position of the knots.

\section{Literacy}

The plot in Fig. 1 fits a model for post-reception literacy score by class size using (1). Here and elsewhere we plot results for the range of class sizes 15-33; outside that range there are only small numbers of classes and the exact relationship is poorly determined.

We see that there is a decreasing test score with increasing class size, with little apparent change between class sizes of about 18 and 25. The details are given in Table II. The lack of linearity is important since it indicates that the effect of a given reduction in class size depends on the actual size of class itself. In particular, as we shall discuss in more detail later, there does seem to be a class size above which any reduction has a relatively small effect. We have fitted a multilevel model allowing for between-pupil,

TABLE II. Post reception literacy score by class size using model (1).

Variance components model

\begin{tabular}{|c|c|c|}
\hline & Estimate & Standard error \\
\hline \multicolumn{3}{|l|}{ Fixed } \\
\hline Intercept & -0.54 & 0.18 \\
\hline Class size & -0.30 & 0.10 \\
\hline Class size ${ }^{2}$ & -0.036 & 0.017 \\
\hline Class size ${ }^{3}$ & -0.0014 & 0.0008 \\
\hline Upper cubic spline & 0.0029 & 0.0012 \\
\hline Lower cubic spline & 0.0027 & 0.0022 \\
\hline \multicolumn{3}{|l|}{ Random } \\
\hline Between school variance & 0.096 & 0.027 \\
\hline Between class variance & 0.142 & 0.024 \\
\hline Between pupil variance & 0.771 & 0.015 \\
\hline$-2^{*}$ loglikelihood & 15662.3 & \\
\hline
\end{tabular}

Class size is the regular class size averaged over all three terms that a child was in the school. Measured about an origin of 30 .

Squared and cubic terms are fitted as indicated. 5870 children used in analysis. 
TABLE III. Post-reception literacy score by class size using model (1) adjusting for baseline literacy score. Variance components model

\begin{tabular}{lcc}
\hline & Estimate & Standard error \\
\hline Fixed & & \\
Intercept & -0.524 & \\
Class size & -0.205 & 0.090 \\
Class size $^{2}$ & -0.019 & 0.015 \\
Class size $^{3}$ & -0.0007 & 0.0007 \\
Upper cubic spline $_{\text {Lower cubic spline }}$ & 0.0016 & 0.0011 \\
Baseline literacy score $^{2}$ & 0.0026 & 0.0026 \\
(Baseline literacy score) $^{2}$ & 0.760 & 0.011 \\
Random & 0.069 & 0.007 \\
Between school variance & & \\
Between class variance & 0.130 & 0.028 \\
Between pupil variance & 0.124 & 0.020 \\
- 2*loglikelihood & 0.364 & 0.007 \\
\hline
\end{tabular}

Class size is the regular class size averaged over all three terms that a child was in the school. Measured about an origin of 30 .

5374 children used in analysis

between-classroom and between-school variation, where the latter accounts for most of the variation, followed by that at the classroom level. In later models, we will introduce random coefficients also. We now carry out an adjustment for the baseline literacy test score using linear and quadratic terms.

Table III and Fig. 2 show the same relationship for the adjusted post-reception score, but this time there is a steady decrease of adjusted score with class size. This plot is at the mean of the baseline literacy score. Since Fig. 2 adjusts for prior achievement, it may be that there is purposive selection of children perceived to have lower prior achievement into smaller classes in the range 18-25 and that the adjustment corrects for this.

Adjusting for baseline literacy score may not adequately remove any association between prior achievement and purposive class size assignment. In the next model, therefore (Table IVa and IVb), we have also adjusted for baseline mathematics score as

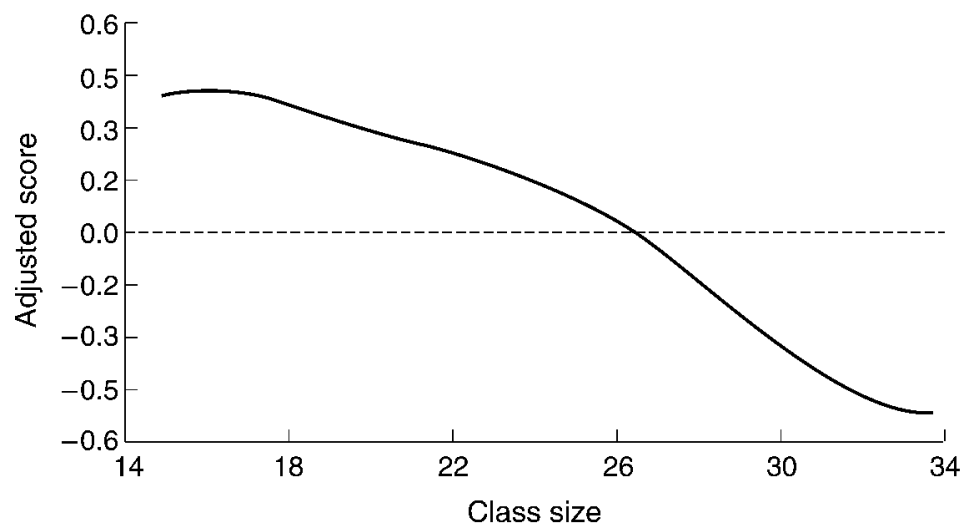

FIG 2. Adjusted post-literacy by class size (knots at 19, 25). 
TABLE IVa. Post reception literacy score by class size using model (1) adjusting for baseline literacy score, term of entry, free school meals, class average baseline literacy score, mathematics baseline, age and gender. Random coefficients model.

\begin{tabular}{|c|c|c|}
\hline & Estimate & Standard error \\
\hline \multicolumn{3}{|l|}{ Fixed } \\
\hline Intercept & -0.011 & 0.163 \\
\hline Class size (a) & -0.062 & 0.085 \\
\hline 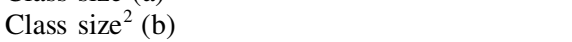 & -0.0064 & 0.013 \\
\hline Class size ${ }^{3}$ & -0.0004 & 0.0006 \\
\hline Upper cubic spline & 0.0009 & 0.0010 \\
\hline Lower cubic spline & 0.0016 & 0.0019 \\
\hline Literacy baseline score (c) & 0.336 & 0.069 \\
\hline$(\text { Literacy baseline score })^{2}(\mathrm{~d})$ & 0.062 & 0.023 \\
\hline Mathematics baseline score & 0.300 & 0.021 \\
\hline \multicolumn{2}{|l|}{ Literacy baseline score-year group average } & 0.065 \\
\hline $\begin{array}{l}\text { (Literacy baseline score-year group average } \\
\text { score })^{2}\end{array}$ & -0.034 & 0.019 \\
\hline Entry in spring or summer* (e) & -0.622 & 0.043 \\
\hline Eligible for free meals*(f) & -0.021 & 0.034 \\
\hline Boy* (g) & -0.035 & 0.016 \\
\hline Age in years on 1 September of reception year & 0.017 & 0.035 \\
\hline Literacy middle group** $(\mathrm{h})$ & -0.067 & 0.049 \\
\hline Literacy high group** (i) & -0.070 & 0.066 \\
\hline Mathematics middle group** $(\mathrm{j})$ & 0.024 & 0.045 \\
\hline Mathematics high group** $(\mathrm{k})$ & 0.026 & 0.063 \\
\hline \multicolumn{3}{|l|}{ Interactions } \\
\hline (a) $\times(\mathrm{h})$ & -0.037 & 0.013 \\
\hline (a) $\times$ (i) & -0.044 & 0.017 \\
\hline (a) $\times$ (j) & 0.010 & 0.006 \\
\hline (a) $\times(\mathrm{k})$ & 0.023 & 0.008 \\
\hline (b) $\times(\mathrm{h})$ & -0.003 & 0.001 \\
\hline (b) $\times$ (i) & -0.006 & 0.003 \\
\hline (c) $\times(\mathrm{e})$ & 0.180 & 0.027 \\
\hline (d) $\times(e)$ & 0.054 & 0.021 \\
\hline (a) $\times$ (f) & 0.008 & 0.011 \\
\hline (b) $\times$ (f) & -0.0003 & 0.0010 \\
\hline
\end{tabular}

Class size is the regular class size average d over all three terms that a child was in the school. Measured about an origin of 30 .

4833 children used in analysis

Variables marked * are dummy $(0,1)$ variable s where the variable name indicate s the category coded 1 .

Variables marked $* *$ are categorie s for baseline scores such that lowest category (the base category) is the lowest $25 \%$, the middle is the next $50 \%$ and the high is the top $25 \%$.

\section{Likelihood ratio tests:}

Interaction with term of entry; $\chi^{2}=45.7$ ( $\left.2 \mathrm{df}\right), p<<0.001$.

Interaction with eligibility for free school meals; $\chi^{2}=3.6(2 \mathrm{df}), p=0.17$.

Interaction with literacy and mathematic groups; $\chi^{2}=(6 \mathrm{df}), p=0.003$.

Significance tests for variable s not involved in interaction s can be obtaine d from the estimated standard errors. 
TABLE IVb. Random parameters. Covariance matrices (standard error in brackets)

\begin{tabular}{lccrr}
\hline & Intercept & Class size & Literacy baseline & (Literacy baseline $)^{2}$ \\
\hline Between-schools & & & & \\
Intercept & $0.15(0.031)$ & & & \\
Class size & $0.006(0.003)$ & $0.0010(0.0004)$ & & \\
Literacy baseline & $-0.045(0.009)$ & $0.0002(0.0011)$ & $0.0224(0.0045)$ & \\
(Literacy baseline) $^{2}$ & $-0.024(0.006)$ & $-0.0010(0.0007)$ & $-0.0002(0.0020)$ & $0.0061(0.0018)$ \\
Between class variance & \multicolumn{2}{c}{$0.063(0.011)$} & & \\
Between pupil variance & $0.290(0.006)$ & & \\
$-2^{*}$ loglikelihood & 8450.6 & &
\end{tabular}

Likelihood ratio tests:

Coefficient of square of literacy baseline score; $\chi^{2}=54.0$ (4 df), $p<<0.001$.

Coefficient of class size; $\chi^{2}=11.1$ ( $\left.4 \mathrm{df}\right), p=0.03$.

well as a number of factors such as the child's age and term of entry. We have allowed the relationship between the end of reception score and the baseline tests to vary with term of entry. We have also included a compositional variable, namely, the average literacy achievement of the pupil's year group in terms of the difference between the pupil's own achievement score and that of the year group. As mentioned earlier, we may expect an interaction between class size and disadvantage. We have therefore fitted eligibility for free school meals and its interaction with class size and also divided the sample into three groups according to their baseline literacy score-the lowest $25 \%$, the middle $50 \%$ and the highest $25 \%$ - and fitted the interaction of this categorisation and class size. This then allows us to plot separate relationships for these groups. Fig. 3 and Table III show the results of this model. We have only shown plots for the three literacy categories since the free meals categorisation produces no further differential effects. Note also that these relationships are adjusted for the other factors, including the basic prior literacy and mathematics scores, so that the differences between the lines cannot be interpreted as differences between groups. Likewise, the vertical scale is for calibration only since the plots are taken at the zero values of the other factors. For free school meals, however, the vertical distance can be interpreted in terms of a group difference.

What we see is that for the highest and middle achievers at baseline, there is a continuing decrease in achievement with increasing class size, but beyond a class size of about 28 this does not continue for the lowest achieving group. Below a class size of about 25 , the gain from a reduction in a class size of 10 is about 0.5 standardised score points for the lowest achieving group, but in the same range is only about 0.2 points for the other pupils. The free meals plot shows a somewhat steeper relationship for those eligible for free school meals, but an overall advantage in small classes for those not eligible.

There are a number of other features of this model worth mentioning. One is the relationship with the compositional variable, namely, the deviation of the prior achievement from the year group prior achievement mean. Fig. 4 is a plot of the adjusted score against this difference, with details in Table 4a. The individual pupil prior literacy score has been adjusted for and it is interesting to note that there is a strong effect the further below the year group mean a pupil is whereas there is relatively little effect as a pupil moves above the mean. There are no significant interactions with the prior literacy score itself. Note also that boys achieve less progress than girls. 

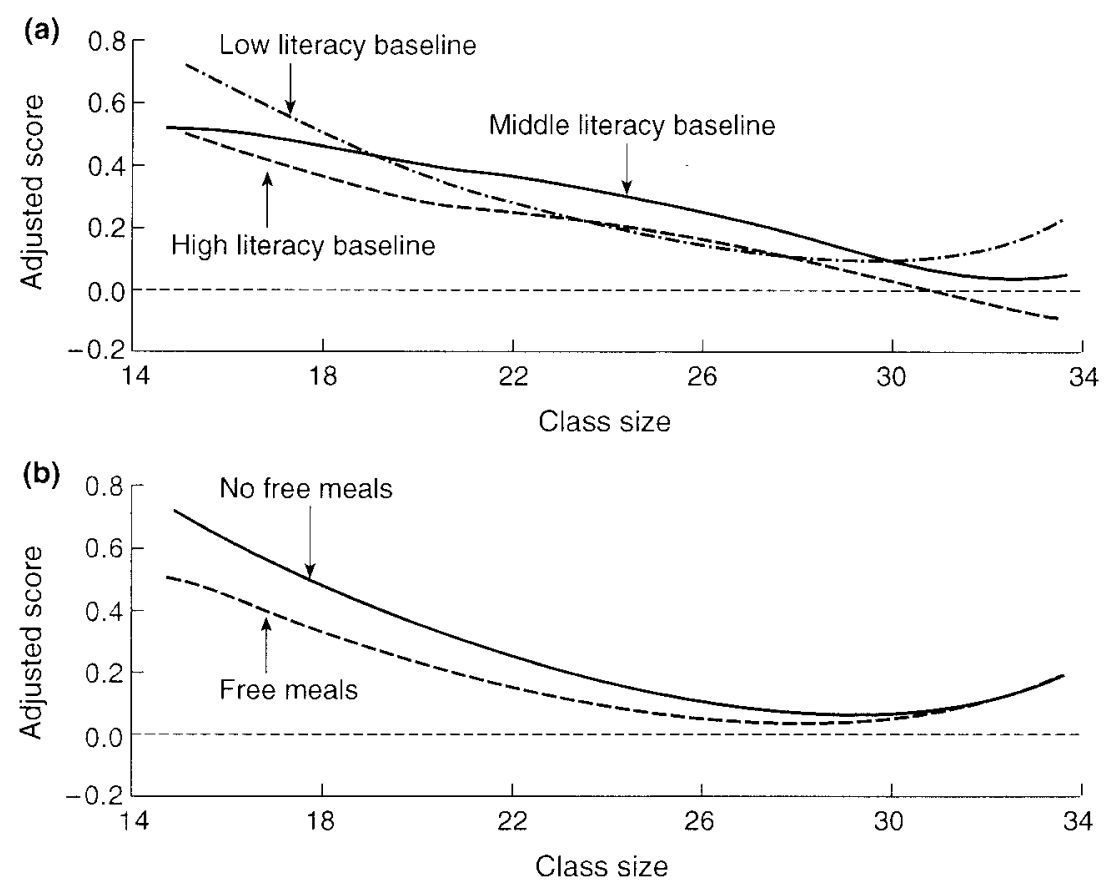

FIG 3. Reception literacy by class size for (a) three baseline groups, and (b) two FSM groups.

Also of interest for educational policy is the effect of spring/summer entry, after adjusting for age. Fig. 5 shows that only for the high achievers at entry is there little difference; as the entry achievement decreases, so the discrepancy between the autumn and later entry pupils increases, being 0.6 standardised score points at the mean achievement level.

\section{Mathematics}

For mathematics, we have followed a similar series of analyses. Fig. 6 and Table V show the basic relationship for end of reception mathematics by class size. The knots for the

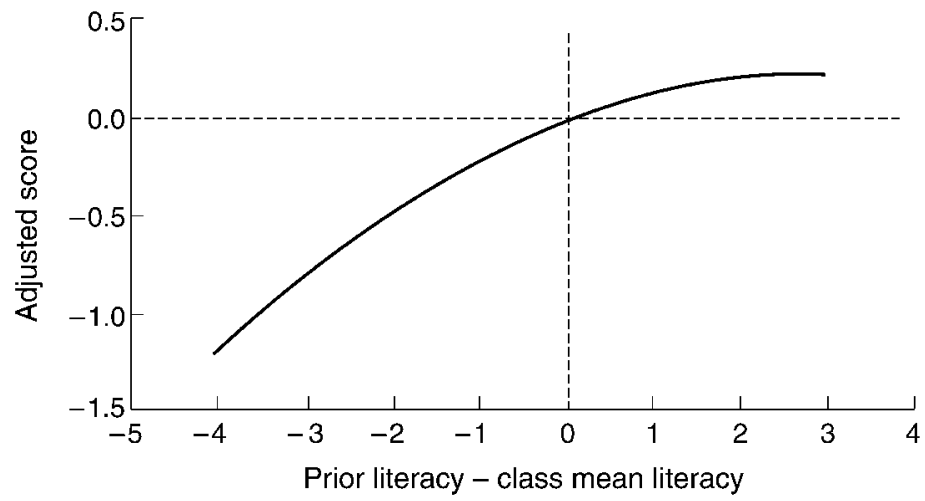

FIG 4. Post-reception literacy by deviation from year group mean. Note: relationship drawn for combination of base categories at mean prior literacy score. 


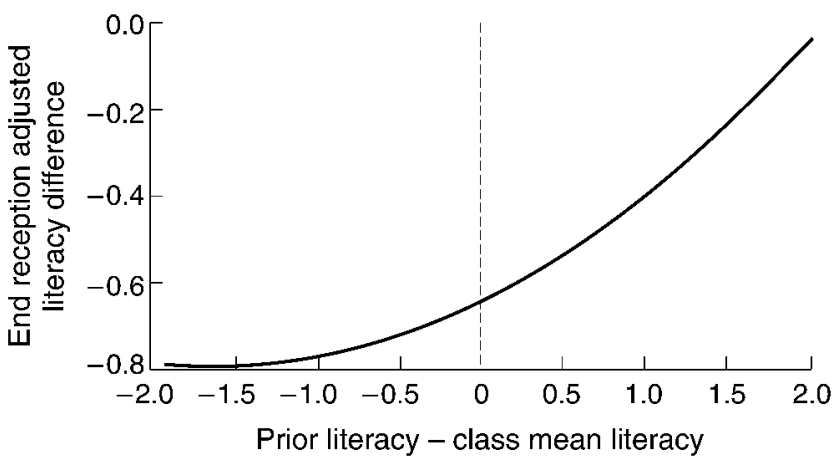

FIG 5. Spring/summer entry-Autumn by end reception literacy. Note: relationship drawn for combination of base categories at mean prior literacy score.

curve are chosen to be the same as for literacy, and again the results are robust against changes to these. As with literacy, there appears to be only a small amount of change for class sizes from about 20 to 25 , with a clearer relationship emerging after adjusting for baseline achievements (Table VI and Fig. 7).

Fig. 8 and Tables VIIa and VIIb show the pattern after adjusting for the same set of other factors as for literacy, including baseline literacy achievement. For mathematics, there is no interaction with class size. Like literacy, it is the low achievers at baseline who appear to have a larger effect from being in a small class, with an increasing reduction in expected achievement up to a class size of about 30 . For the middle and high baseline pupils there is little change above a class size of about 22 .

Fig. 9 shows the relationship between adjusted score and deviation from the class mean baseline mathematics achievement. The pattern is similar to that for literacy. For boys, now the coefficient is statistically not significantly different from zero. As with literacy, a spring or summer entry is associated with lower adjusted achievement and

TABLE V. Post-reception mathematics score by class size using model (1). Variance components model

Estimate $\quad$ Standard error

\section{Fixed}

Intercept

Class size

$-0.840$

Class size ${ }^{2}$

$-0.483$

0.161

Class size $^{3}$

Upper cubic spline

$-0.074$

$-0.004$

0.026

0.0053

0.001

Lower cubic spline

0.0277

0.0021

0.0013

\section{Random}

Between school variance

$\begin{array}{ll}0.065 & 0.026 \\ 0.161 & 0.027 \\ 0.764 & 0.015\end{array}$

Between class variance

Between pupil variance

$-2 * \log l i k e l i h o o d$

Class size is the regular class size averaged over all three terms that a child was in the school. Measured about an origin of 30 .

5560 children used in analysis. 


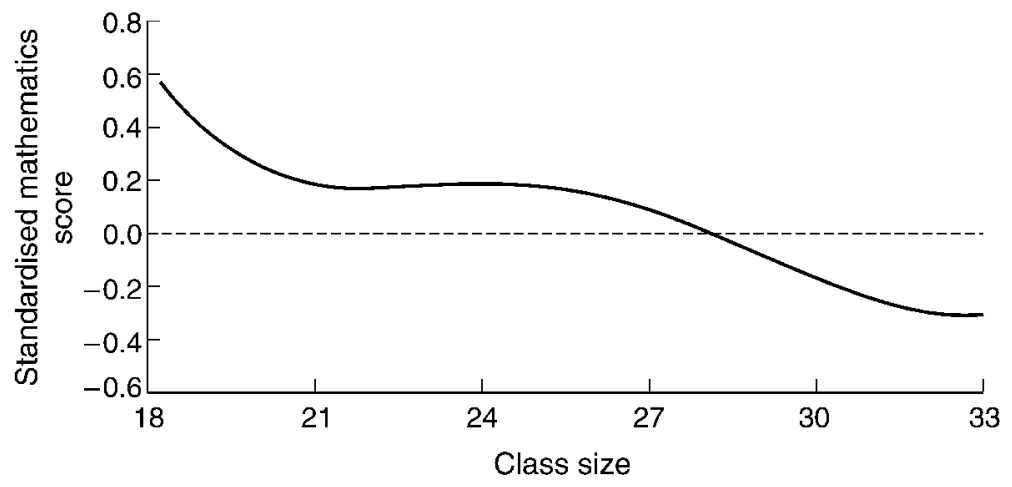

FIG 6. Post-reception maths score by class size (knots at 19, 25).

with all prior achievement levels being associated with a substantially lower achievement: about 0.3 standardised units at the mean achievement level (Fig. 10).

\section{Discussion}

We know from many studies a good deal about the main factors influencing children's progress after entry to school (e.g. Tizard et al., 1988). We know that children's skills and knowledge on entry to school are important determinants of such progress, and we know that income levels (e.g. as indicated by free school meal eligibility) and gender are also important. We also know that home influences and parental input are important, as are endogenous or within-child factors, such as intelligence and ability to concentrate. Over and above these influences, the influence of school experiences is bound to be

TABLE VI. Post-reception mathematics score by class size, adjusting for baseline mathematics and literacy scores. Variance components model

\begin{tabular}{lcc}
\hline & Estimate & Standard error \\
\hline Fixed & & \\
Intercept & -0.675 & \\
Class size & -0.350 & 0.134 \\
Class size & -0.051 & 0.022 \\
Class size $^{3}$ & -0.0027 & 0.0010 \\
Upper cubic spline $^{2}$ & 0.0036 & 0.0017 \\
Lower cubic spline & 0.0323 & 0.0087 \\
Baseline literacy score & 0.352 & 0.017 \\
${\text { (Baseline literacy score })^{2}}_{\text {Baseline mathematics score }}$ & -0.005 & 0.009 \\
${\text { (Baseline mathematics score })^{2}}$ & 0.379 & 0.017 \\
Random & 0.012 & 0.009 \\
Between school variance & & 0.026 \\
Between class variance & 0.097 & 0.022 \\
Between pupil variance & 0.136 & 0.008 \\
- 2*loglikelihood & 0.384 & \\
\hline
\end{tabular}

Class size is the regular class size averaged over all three terms that a child was in the school. Measured about an origin of 30 .

5143 children used in analysis 


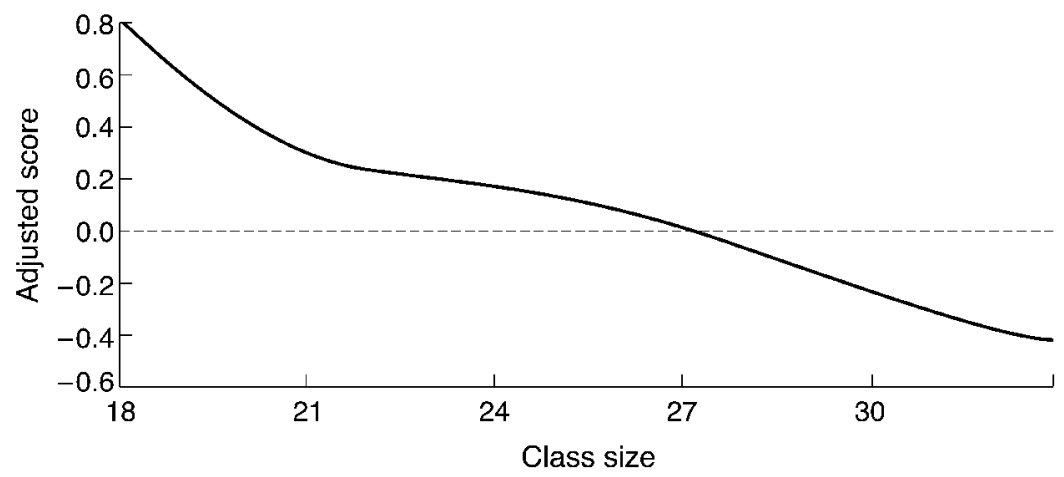

FIG 7. Adjusted post-reception maths score by class size (knots at 19, 25).

relatively small, and, as part of that, the influence of class size is bound to be even smaller. Given this, the effect of class size that we find in this study can be seen as impressive. These analyses have demonstrated a clear effect of class size difference on children's academic attainment over the reception year, both before and after adjusting for possible confounding factors. They have also shown some differential effects for the initial low achievers in the case of literacy and for those eligible for free school meals. For mathematics, the pattern is somewhat different than for literacy, most noticeably in the small amount of change for class sizes between 25 and 30. As we suggested in the introduction, there remains the possibility that further confounding factors exist which could modify our conclusions. Strictly speaking, results may not generalise to other parts of the UK where education policy and practice may vary. These are areas for further research, but our view is that the present study provides the most extensive prima facie evidence for the existence of a real causal effect of class size on achievement.

The average change of post-reception mathematics score with age is 0.73 standardised points per year. This is the 'contemporaneous' rate of change and is not the same as the average change that an average pupil will achieve over 1 year. Goldstein \& Fogelman (1974) estimate the ratio of the latter to the former, at age 11 , to be 2.6 and if this were applied here it would imply that a difference of 1 standardised point was equivalent to about 2 years' progress. For literacy, the corresponding number of years for a difference of 1 standardised score point is estimated to be 1.7 years, resulting in an estimated

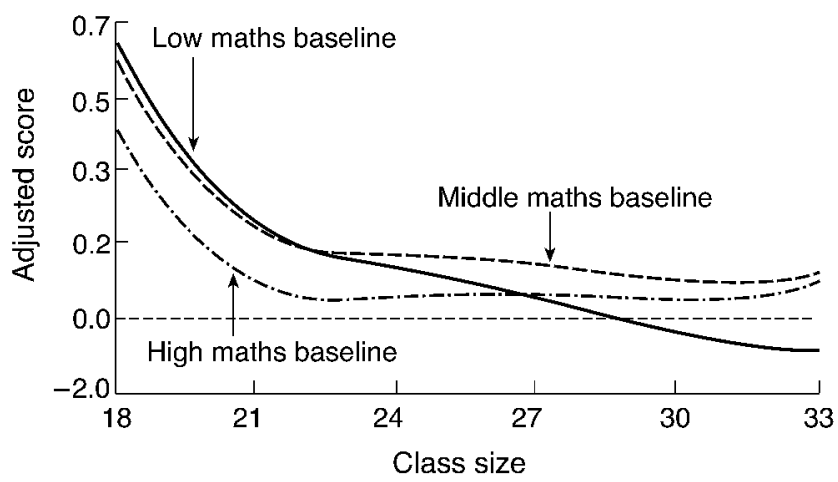

FIG 8. Adjusted post-reception maths score by class size for three baseline groups. 
TABLE VIIa. Post-reception mathematics score by class size using model (1) adjusting for baseline literacy score, term of entry, free school meals, class average baseline literacy score, mathematics baseline, age and gender. Random coefficients model.

\begin{tabular}{|c|c|c|}
\hline & Estimate & Standard error \\
\hline \multicolumn{3}{|l|}{ Fixed } \\
\hline Intercept & -0.320 & \\
\hline Class size (a) & -0.197 & 0.130 \\
\hline Class $\operatorname{size}^{2}(\mathrm{~b})$ & -0.032 & 0.021 \\
\hline Class size ${ }^{3}$ & -0.0019 & 0.0010 \\
\hline Upper cubic spline & 0.0023 & 0.0017 \\
\hline Lower cubic spline & 0.0192 & 0.0080 \\
\hline Mathematics baseline score (c) & 0.072 & 0.071 \\
\hline$(\text { Mathematic s baseline score) })^{2}(\mathrm{~d})$ & 0.072 & 0.023 \\
\hline Literacy baseline score & 0.342 & 0.017 \\
\hline$(\text { Literacy baseline score })^{2}$ & -0.010 & 0.009 \\
\hline $\begin{array}{l}\text { Mathematics baseline score-year group } \\
\text { average score }\end{array}$ & 0.288 & 0.067 \\
\hline $\begin{array}{l}\text { (Mathematics baseline score-year group } \\
\text { average score })^{2}\end{array}$ & -0.065 & 0.018 \\
\hline Entry in spring or summer* (e) & -0.525 & 0.048 \\
\hline Eligible for free meals* & -0.086 & 0.028 \\
\hline Boy* & -0.005 & 0.018 \\
\hline $\begin{array}{l}\text { Age in years on } 1 \text { September of reception } \\
\text { year (centred at } 4.0)\end{array}$ & 0.134 & 0.040 \\
\hline Mathematics middle group** (j) & 0.123 & 0.053 \\
\hline Mathematics high group $* *(\mathrm{k})$ & 0.079 & 0.072 \\
\hline \multicolumn{3}{|l|}{ Interactions: } \\
\hline (a) $\times$ (j) & 0.015 & 0.008 \\
\hline (a) $\times(\mathrm{k})$ & 0.024 & 0.009 \\
\hline (c) $\times(e)$ & 0.095 & 0.030 \\
\hline (d) $\times(\mathrm{e})$ & 0.0002 & 0.023 \\
\hline
\end{tabular}

Class size is the regular class size average d over all three terms that a child was in the school. Measured about an origin of 30 .

4691 children used in analysis

Variables marked $*$ are dummy $(0,1)$ variables where the variable name indicate s the category coded 1 .

Variables marked $* *$ are categorie s for baseline scores such that lowest category (the base category) is the lowest $25 \%$, the middle is the next $50 \%$ and the high is the top $25 \%$.

Likelihood ratio tests:

Interaction with term of entry; $X^{2}=11.0(2 \mathrm{df}), p=0.004$.

Interaction with mathematics groups; $X^{2}=6.2(2 \mathrm{df}), p=0.05$.

Significance tests for variables not involved in interaction s can be obtained from the estimated standard errors.

gender difference in favour of girls of about 4 months. For literacy, this would also imply that a decrease of class size of 10 , below 25 , is associated with a gain of about one year's achievement for the lowest achieving group and about 5 months for other pupils. These estimates are impressive, though very rough and should be treated with caution. 
TABLE VIIb. Random parameters. Covariance matrices (standard error in brackets)

\begin{tabular}{lrcc}
\hline & Intercept & Mathematics baseline & ${\text { (Mathematics baseline })^{2}}^{2}$ \\
\hline Between-schools & & & \\
Intercept & $0.083(0.023)$ & & \\
Mathematics baseline & $-0.017(0.006)$ & $0.008(0.003)$ & $0.007(0.002)$ \\
(Mathematics baseline) $^{2}$ & $-0.016(0.005)$ & $0.002(0.002)$ & $0.100(0.017)$ \\
Between class variance & & $0.359(0.008)$ \\
Between variance & & 9141.3 \\
$-2 *$ loglikelihood & & & \\
\hline
\end{tabular}

Likelihood ratio test:

Coefficient of square of mathematics baseline score $X^{2}=36.0$ (3 df), $p<<0.001$.

There are important policy implications of these results. In general, the results support the use of small classes during KS1, or, more precisely, during the first, reception year. However, the results also allow a more specific picture in terms of the children who most benefit. We have found evidence that small classes appear to work best in literacy for children who are most in need academically; that is, those with the lowest school entry scores who thus have the most ground to make up. For small class sizes, there is an advantage to those not eligible for free meals. Both findings, i.e. concerning achievement levels on entry and income levels, suggest where targeting of resources (in this case small classes and those on relatively low incomes) might be best directed.

The picture is more complicated when it comes to judgements about optimum class sizes. For mathematics and for the lowest attainers in literacy there is a tendency for class size effects to be most marked from 25 and smaller. There are other indications in our study that 25 may be an important number of children, below which relationships with classroom processes, such as the number and size of within-class groups, become most evident (Blatchford et al., 2001). This might be contrasted with results from US studies which suggest that class sizes below 20 are crucial for effects to be found; however, as we have seen, studies such as the STAR project are limited in that they do not allow relationships between attainment and class size to be tested across the full range of class sizes.

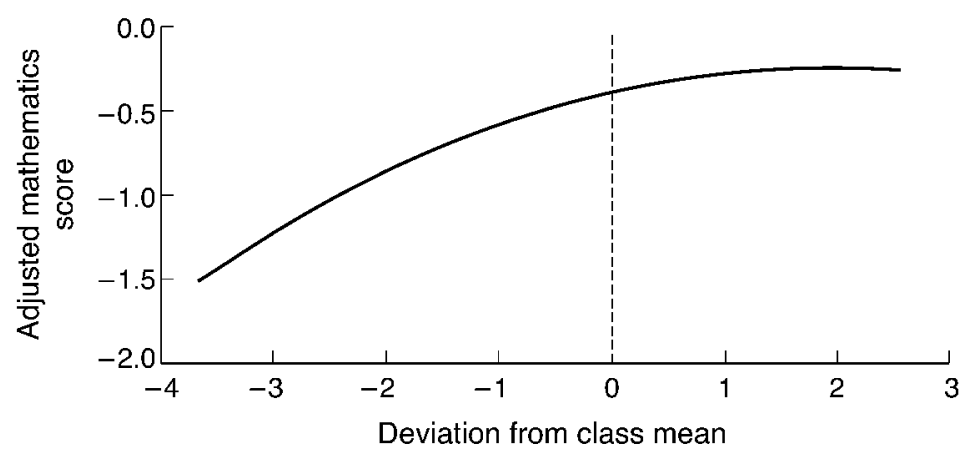

FIG 9. Post-reception mathematics by deviation from year group mean. Note: relationship drawn for combination of base categories at mean prior mathematics score. 


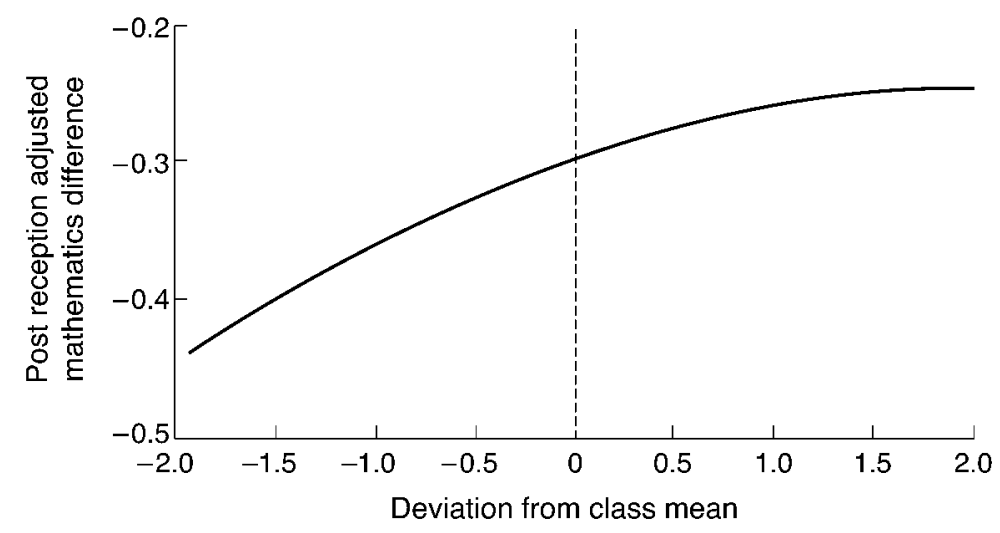

FIG 10. Spring/summer entry-Autumn by end reception mathematics. Note: relationship drawn for combination of base categories at mean prior mathematics score.

In future articles, we will extend our analysis in a number of ways. Statistical models will be extended to allow for the possible influences of other compositional features of the class; for example, it might be expected that for a given size of class, a child will make more progress if the average ability level of the class is higher, and, conversely, less progress if there are more children who are financially poor, are achieving poorly at pre-test, and have behavioural difficulties. We will also include in models information on classroom processes and behaviour. In other articles, we show that class size differences are related to several aspects of classroom processes, including teacher-pupil interactions, pupil attentiveness and peer relations (Blatchford, et al., submitted for publication), teaching (Blatchford et al., in press) and within class grouping practices (Blatchford et al., 2001). A next step is to include information on these and other processes into models predicting progress to examine to what extent they mediate, or explain, the class size effect. In addition, the progress made during years 1 and 2 in relation to class size is being studied and will be reported elsewhere. A preliminary analysis of the effects of extra staff and adults generally has been carried out, but these variables appear to show no additional effect for either literacy or mathematics, once the other variables in the analysis have been included. Further work on this topic is in progress. Finally, these models will be replicated on the second cohort and a combined analysis will be produced based on larger numbers of classes and pupils.

Correspondence: Professor P. Blatchford, Institute of Education, 20 Bedford Way, London WC1H 0AL, UK; e-mail: p.blatchford@ioe.ac.uk

\section{REFERENCES}

Avon Reception Entry Assessment (1996) (Avon Education Department and the Institute of Education).

Blatchiord, P. \& Mortimore, P. (1994) The issue of class size for young children in schools: what can we learn from research? Oxford Review of Education, 20, pp. 411-428.

Blatchford, P., Baines, E., Kutnick, P. \& Martin, C. (2001) Classroom contexts: connection s between class size and within class grouping, British Journal of Educational Psychology, 71, pp. $283-302$.

BlatchFord, P., Edmonds, S. \& Martin, C. Class size, pupil attentivenes s and peer relations (submitted). 
Blatchford, P., Goldstein, H. \& Mortimore, P. (1998) Research on class size effects: a critique of methods and a way forward, International Journal of Educational Research, 29, pp. 691-710.

Blatchford, P., Moriarty, V., Edmonds, S. \& Martin, C. (in press) Relationships between class size and teaching: a multi-method analysis of English infant schools, American Educational Research Journal.

FInN, J. D. \& Achilles, C. M. (1999) Tennessee's class size study: findings, implications, misconceptions, Educational Evaluation and Policy Analysis, 21(2), pp. 97-109.

Goldstein, H. \& BlatchFord, P. (1998) Class size and educational achievement: a review of methodology with particular reference to study design, British Educational Research Journal, 24, pp. 255-268.

Goldstein, H. \& Fogelman, K. (1974) Age standardisation and seasonal effects in mental testing, British Journal of Mathematical and Statistical Psychology, 44, pp. 109-115.

Hastie, T. J. \& Tibshirani, R. J. (1990) Generalized Linear Models (London, Chapman \& Hall.).

Molnar, A., Smith, P., Zahorik, J., Palmer, A., Halbach, A. \& Ehrle, K. (1999) Evaluating the SAGE program: a pilot program in targeted pupil-teacher reduction in Wisconsin, Educational Evaluation and Policy Analysis, 21(2), pp. 165-177.

Reading Progress Tests (2000) Literacy Baseline (London, Hodder \& Stoughton).

Slavin, R. (1989) Class size and student achievement: small effects of small classes, Educational Psychologist, 24, pp. 99-110.

Tizard, B., Blatchford, P., Burke, J., Farquhar, C. \& Plewis, I. (1988) Young Children at School in the Inner City (Hove, Local Education Authority).

Word, E. R., Johnston, J., Bain, H. P. \& Fulton, B. D. (1990) The State of Tennessee's Student/Teacher Achievement Ratio (STAR) Project: technical report 1985-90 (Nashville, TN, Tennessee State University).

Yang, M., Goldstein, H., Omar, R., Turner, R. \& Thompson, S. G. (2000) Meta analysis using multilevel models with an application to the study of class size effects, Journal of the Royal Statistical Society, Series C, 49, pp. 1-14. 